\section{Monomeric Sn(II) and Ge(II) hydrides supported by a tridentate pincer-based ligand $\dagger \ddagger$}

\author{
Shabana Khan, ${ }^{a}$ Prinson P. Samuel, ${ }^{a}$ Reent Michel, ${ }^{a}$ Johannes M. Dieterich, ${ }^{b}$ \\ Ricardo A. Mata, ${ }^{* b}$ Jean-Philippe Demers, ${ }^{c}$ Adam Lange, ${ }^{c}$ Herbert W. Roesky ${ }^{* a}$ and \\ Dietmar Stalke $* a$
}

Received 17th February 2012, Accepted 12th March 2012

DOI: $10.1039 / \mathrm{c} 2 \mathrm{cc} 31214 \mathrm{j}$

Herein we report the syntheses of terminal $\mathrm{Sn}$ (II) (3) and $\mathrm{Ge}(\mathrm{II})$ (4) hydrides from the corresponding chloride precursors $\left[\left\{2,6-i \mathrm{Pr}_{2} \mathrm{C}_{6} \mathrm{H}_{3} \mathrm{NCMe}\right\}_{2} \mathrm{C}_{6} \mathrm{H}_{3} \mathrm{MCl}\right](\mathrm{M}=\mathrm{Sn}$ (1), Ge (2)) using $\left[\mathrm{K}\left\{\mathrm{B}(\text { sec- } \mathrm{Bu})_{3}\right\} \mathrm{H}\right]$ as a hydrogenating agent. Combination of steric shielding and intramolecular $\mathbf{N} \rightarrow \mathbf{M}$ interactions resulted in the protection of $\mathrm{M}(\mathrm{II})-\mathrm{H}$ bonds.

Main group metal hydrides are extremely important in chemical synthesis. They are notably used as precursors for the preparation of other metal hydrides, as reducing agents for a big variety of inorganic and organic substrates and function as potential feedstocks for hydrogen storage. ${ }^{1,2}$ Hydrides are considered as promising candidates for the synthesis of new clusters and nanoparticles by controlled thermolysis. ${ }^{3}$ By taking advantage of sterically bulky terphenyl ligands Power et al. isolated the first $\mathrm{Sn}(\mathrm{II})$ hydride $\left[\left\{2,6-\mathrm{Trip}_{2} \mathrm{C}_{6} \mathrm{H}_{3} \mathrm{Sn}(\mu-\mathrm{H})\right\}_{2}\right.$, Trip = 2,4,6-i $\operatorname{Pr}_{3} \mathrm{C}_{6} \mathrm{H}_{2}$ ]. However, this compound is dimeric with bridging hydrogen atoms. ${ }^{4}$ The first dimeric structurally characterized $\mathrm{Ge}(\mathrm{II})$ hydride $[\mathrm{ArGeH}]_{2}\left(\mathrm{Ar}=2,6-\mathrm{Dipp}_{2} \mathrm{C}_{6} \mathrm{H}_{3}\right.$, Dipp $=$ 2,6-i $\operatorname{Pr}_{2} \mathrm{C}_{6} \mathrm{H}_{3}$ ) was reported by the same group. ${ }^{5}$ Moreover in 2006, the first structurally characterized terminal $\mathrm{Sn}$ (II) and $\mathrm{Ge}(\mathrm{II})$ hydrides $\left[\left\{\mathrm{HC}(\mathrm{CMeNAr})_{2}\right\} \mathrm{MH}, \mathrm{Ar}=2,6-i \mathrm{Pr}_{2} \mathrm{C}_{6} \mathrm{H}_{3}\right.$, $\mathbf{M}=\mathrm{Sn}(\mathbf{A})$ and $\mathrm{Ge}(\mathbf{B})]$ were outlined, but compound $\mathbf{A}$ exhibited weak intermolecular Sn-H..Sn contacts. ${ }^{6}$ In 2011 , Jones et al. reported the synthesis of an analogous Ge(II) hydride $\left[\left\{\mathrm{HC}(\mathrm{CMeNMes})_{2}\right\} \mathrm{GeH},\left(\mathrm{Mes}=2,4,6-\mathrm{Me}_{3} \mathrm{C}_{6} \mathrm{H}_{2}\right)\right.$ (C)] stabilized by a similar $\beta$-diketiminato backbone. ${ }^{7}$ Further attempts to prepare the corresponding tin(II) hydride complex were not successful. ${ }^{7}$ The instability of the tin analogue could

\footnotetext{
${ }^{a}$ Institut für Anorganische Chemie, Georg-August-Universität, Tammannstrasse 4, 37077 Göttingen, Germany.

E-mail:hroesky@gwdg.de,dstalke@chemie.uni-goettingen.de

${ }^{b}$ Institut für Physikalische Chemie, Georg-August-Universität,

Tammannstrasse 6, 37077 Göttingen, Germany.

E-mail:rmata@gwdg.de

${ }^{c}$ Solid-State NMR, Max-Planck-Institut für Biophysikalische Chemie, Am Faßberg 11, 37077 Göttingen, Germany

$\dagger$ This paper is dedicated to Professor Anton Meller on the occasion of his 80th birthday.

$\ddagger$ Electronic supplementary information (ESI) available: Full synthetic, spectroscopic, X-ray crystallographic and theoretical details for $\mathbf{3}$ and $\mathbf{4}$. CCDC 863378 (3) and 863377 (4). For ESI and crystallographic data in CIF or other electronic format see DOI: $10.1039 / \mathrm{c} 2 \mathrm{cc} 31214 \mathrm{j}$
}

be due to the weaker nature of the $\mathrm{Sn}-\mathrm{H}$ bond relative to the $\mathrm{Ge}-\mathrm{H}$ bond. ${ }^{8}$ Apart from these, Rivard et al. recently described the stabilization of the parent $\mathrm{GeH}_{2}$ and $\mathrm{SnH}_{2}$ complexes using a $\mathrm{N}$-heterocyclic carbene (NHC) as a donor and a $\mathrm{BH}_{3}$ or metal carbonyl complex as an acceptor (D-F). ${ }^{9}$ These hydrides are coordinatively saturated because the lone pair of electrons at $\mathrm{Ge}$ and Sn effectively takes part in the coordination (Chart 1). However, in an insertion reaction of $\mathbf{F}$ with benzaldehyde, the $\mathrm{C}: \rightarrow$ Sn bond readily cleaves indicating the lability of the NHC donor. $^{9 b}$

New monomeric Sn(II) hydride could be achieved by increasing the coordination around the Sn(II) center. Very recently, we have reported a pincer supported bis-stannylene ( $\left.\left.\left\{2,6-i \mathrm{Pr}_{2} \mathrm{C}_{6} \mathrm{H}_{3} \mathrm{NCMe}\right\}_{2} \mathrm{C}_{6} \mathrm{H}_{3} \mathrm{Sn}\right]_{2}\right)$ with a $\mathrm{Sn}(\mathrm{I})-\mathrm{Sn}(\mathrm{I})$ bond by reducing $\left[\left\{2,6-i \mathrm{Pr}_{2} \mathrm{C}_{6} \mathrm{H}_{3} \mathrm{NCMe}\right\}_{2} \mathrm{C}_{6} \mathrm{H}_{3} \mathrm{SnCl}\right]$ (1) with $\mathrm{KC}_{8} \cdot{ }^{10}$ So et al. reported the analogous bis-germylene compound using a comparable ligand. ${ }^{11}$ Moreover, Jurkschat et al. outlined the synthesis of $\left[\left\{2,6-\left(\mathrm{Me}_{2} \mathrm{NCH}_{2}\right)_{2} \mathrm{C}_{6} \mathrm{H}_{3}\right\} \mathrm{Sn}(\mathrm{H}) \mathrm{W}(\mathrm{CO})_{5}\right]$, a pincer based $\mathrm{Sn}$ (II) hydride stabilized in the coordination sphere of $\mathrm{W}(\mathrm{CO})_{5}{ }^{12}$ This encouraged us to prepare the hitherto elusive terminal $\mathrm{Sn}(\mathrm{II})$ hydride.

Treatment of compounds $\mathbf{1}$ and $\mathbf{2}$, respectively, with $\mathrm{K}\left[\mathrm{B}(\mathrm{sec}-\mathrm{Bu})_{3} \mathrm{H}\right]$ in $\mathrm{THF}$ at $0{ }^{\circ} \mathrm{C}$ followed by recrystallization in toluene afforded dark reddish-orange colored crystals of $\mathbf{3}$ and $\mathbf{4}$

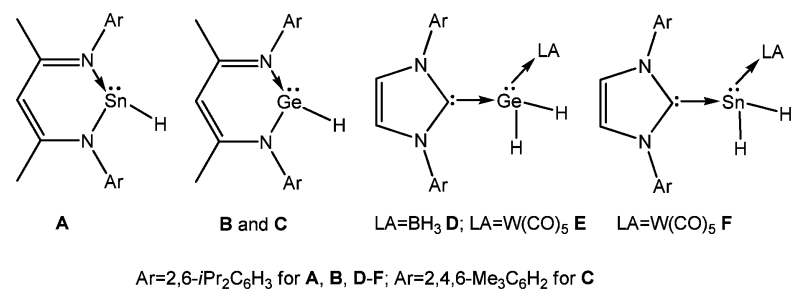

Chart 1 Monomeric Lewis base coordinate Sn(II) and Ge(II) hydrides A-C; Lewis acid and Lewis base coordinate $\mathrm{Sn}$ (II) and Ge(II) hydrides D-F.



Scheme 1 Syntheses of 3 and 4. 
(Scheme 1). Conclusive evidence for the formation of the monomeric hydrides $\mathbf{3}$ and $\mathbf{4}$ was obtained by X-ray crystallography (Fig. 1), NMR and IR spectroscopy, and theoretical calculations. The stabilization of $\mathbf{3}$ and $\mathbf{4}$ may be occurring by increasing the electron density at the empty p orbital of the metal centre from the adjacent nitrogen donors. The most noticeable feature of $\mathbf{3}$ is the absence of any kind of intermolecular interactions ( $\mathrm{Sn}-\mathrm{Sn}$ or $\mathrm{Sn}-\mathrm{H})$ in the crystal packing confirming an exclusively monomeric nature of $\mathrm{Sn}$ (II) hydride. However, the position of the $\mathrm{MH}(\mathrm{M}=\mathrm{Sn}$ and $\mathrm{Ge})$ hydrogen atom cannot be determined reliably. Therefore, the corresponding bond distance and angle are not discussed herein. In both cases the MH moiety is disordered over two positions resulting in a superposition of the electron density of the $\mathrm{M}-\mathrm{H}$ bond and the $\mathrm{Ge}$ and $\mathrm{Sn}$ lone pairs, respectively (for more details see ESI $\ddagger$ ).

Compound $\mathbf{3}$ crystallizes in the monoclinic space group $P c{ }^{13}$ The molecular structure of 3 reveals that the $\mathrm{Sn}$ atom is four-coordinated and exhibits a distorted seesaw geometry considering the lone pair of electrons. The flanking aromatic rings are nearly perpendicular to the central ring of the ligand. The two nitrogen atoms are coordinated intra-molecularly to the Sn atom with bond lengths of 2.4538(13) and 2.4664(14) ̊, respectively, which are consistent with those for intra-molecularly coordinated $\mathrm{Sn}-\mathrm{N}$ bonds. ${ }^{14}$ Similarly, the Sn-C bond length of 3 (2.1665(16) $\AA$ ) is in good accordance with the $\mathrm{Sn}-\mathrm{C}$ bond distances in $\left[\left\{2,6-i \mathrm{Pr}_{2} \mathrm{C}_{6} \mathrm{H}_{3} \mathrm{NCMe}\right\}_{2} \mathrm{C}_{6} \mathrm{H}_{3} \mathrm{Sn}\right]_{2} \quad$ (2.1575(18) and $2.1880(19) \AA)^{10}$ and $\left[\left\{2,6-\left(\mathrm{Me}_{2} \mathrm{NCH}_{2}\right)_{2} \mathrm{C}_{6} \mathrm{H}_{3}\right\} \mathrm{Sn}\right]_{2} \quad(2.180(11)$ and 2.193(10) $\AA$ ). ${ }^{15}$ Compound 4 crystallizes in the monoclinic space group $C 2 / c^{13}$ and adopts an isostructural motif as its $\mathrm{Sn}-\mathrm{H}$ congener 3. The two intra-molecularly coordinated $\mathrm{Ge}-\mathrm{N}$ bond lengths in 4 (2.2722(15) and 2.2746(15) $\AA$ ) are in line with that of $\left[\left\{2,6-i \mathrm{Pr}_{2} \mathrm{C}_{6} \mathrm{H}_{3} \mathrm{NC}(\mathrm{H})\right\}_{2} \mathrm{C}_{6} \mathrm{H}_{3} \mathrm{GeCl}\right]\left(2.247(3) \AA{ }^{\circ}\right) .{ }^{11}$ The Gel-C1 bond length $(1.9483(18) \AA)$ is shorter compared to that of $\left[\left\{2,6-i \mathrm{Pr}_{2} \mathrm{C}_{6} \mathrm{H}_{3} \mathrm{NC}(\mathrm{H})\right\}_{2} \mathrm{C}_{6} \mathrm{H}_{3} \mathrm{GeCl}\right](2.028(3) \AA) .{ }^{11}$

The constitutions of $\mathbf{3}$ and $\mathbf{4}$ derived from single crystal $\mathrm{X}$-ray diffraction studies were further confirmed by spectrochemical analyses. In 3 a sharp singlet appears at $\delta 10.59 \mathrm{ppm}$ with ${ }^{1} J\left({ }^{119} \mathrm{Sn}-{ }^{1} \mathrm{H}\right)=112 \mathrm{~Hz}$ which is shifted to the high field relative to that of $\mathbf{A}(\delta 13.96 \mathrm{ppm})$ but to low field relative to that of $\left[\left\{2,6-\operatorname{Trip}_{2} \mathrm{C}_{6} \mathrm{H}_{3} \mathrm{Sn}(\mu-\mathrm{H})\right\}_{2}\right](\delta 7.87 \mathrm{ppm}) .{ }^{4}$ The corresponding resonance for 4 appears at $\delta 6.69 \mathrm{ppm}$ for the hydrogen attached to germanium $(\mathrm{Ge}-\mathrm{H})$ which is at lower field than those reported for $[\mathrm{ArGeH}]_{2}\left(\mathrm{Ar}=2,6-\mathrm{Dipp}_{2} \mathrm{C}_{6} \mathrm{H}_{3}, \mathrm{Dipp}=2,6-i \mathrm{Pr}_{2} \mathrm{C}_{6} \mathrm{H}_{3}\right)$ ( $\delta 3.48 \mathrm{ppm})$ and $\operatorname{Ar}(\mathrm{H})_{2} \mathrm{GeGeAr} \cdot \mathrm{PMe}_{3}\left(\mathrm{Ar}=2,6-\mathrm{Dipp}_{2} \mathrm{C}_{6} \mathrm{H}_{3}\right.$, Dipp $\left.=2,6-i \operatorname{Pr}_{2} \mathrm{C}_{6} \mathrm{H}_{3}\right)(\delta 3.81 \mathrm{ppm})^{5}$ but shifted to higher field than that reported for $\mathbf{B}(\delta 8.08 \mathrm{ppm}){ }^{6 a}$ The low field chemical



Fig. 1 Molecular structures of $\mathbf{3}$ and 4. Anisotropic displacement parameters are depicted at the $50 \%$ probability level. Hydrogen atoms except the ones attached to $\mathrm{Sn} 1$ and Ge1, lattice toluene molecules and the disordered $\mathrm{Sn}-\mathrm{H}$ and $\mathrm{Ge}-\mathrm{H}$ moieties are not shown for clarity. The Sn1-H1 and Ge1-H1 distances were set to the theoretical data. shift of $\mathbf{3}$ compared to that of $\mathbf{4}$ is similar to those found in $\mathbf{A}$ and $\mathbf{B}$ and presumably due to the less electron transfer from the nitrogen atoms to the $\mathrm{Sn}-\mathrm{H}$ bond than that within the Ge-H bond. ${ }^{6 a}$ The ${ }^{119} \mathrm{Sn}$ NMR spectrum of 3 exhibits a singlet $(\delta-114.27 \mathrm{ppm})$ with a coupling constant of ${ }^{1} J_{\mathrm{Sn}-\mathrm{H}}=112.9 \mathrm{~Hz}$. The chemical shift is high field shifted when compared with $\mathbf{A}$ $(\delta-4.45 \mathrm{ppm})$ and the precursor $4(\delta-20 \mathrm{ppm})$. The $\mathrm{Sn}-\mathrm{H}$ coupling constant is in line with that of $\mathbf{A}\left({ }^{1} J_{\mathrm{Sn}-\mathrm{H}}=45 \mathrm{~Hz}\right)$ and with several dimeric tin(II) hydrides $\left({ }^{1} J_{\mathrm{Sn}-\mathrm{H}}=87-95 \mathrm{~Hz}\right)$ reported previously. ${ }^{16}$ In all the cases, Sn centres carry a lone pair of electrons. However the value of the coupling constant is significantly smaller than that of $\mathbf{F}\left({ }^{1} J_{\mathrm{Sn}-\mathrm{H}}=1158 \mathrm{~Hz}\right)$ and $\left[\left\{2,6-\left(\mathrm{Me}_{2} \mathrm{NCH}_{2}\right)_{2} \mathrm{C}_{6} \mathrm{H}_{3}\right\} \mathrm{Sn}(\mathrm{H}) \mathrm{W}(\mathrm{CO})_{5}\right](1302 \mathrm{~Hz})^{12}$ where the lone pair at the $\mathrm{Sn}$ centre coordinates to a Lewis acid. This indicates that the coupling constant is strongly influenced by the nature of surrounding ligands at the $\mathrm{Sn}$ centre. The solid-state CPMAS NMR of 3 (See ESI $\ddagger$, Fig. S6), which shows a single ${ }^{119} \mathrm{Sn}$ resonance at $-119.4 \mathrm{ppm}$, supports the assignment of a monomeric structure for $\mathbf{3}$ both in solution and in the solid state. In the IR spectra of $\mathbf{3}$ and $\mathbf{4}$, strong absorptions were observed at $1826 \mathrm{~cm}^{-1}$ and $1985 \mathrm{~cm}^{-1}$ which are tentatively assigned to the $\mathrm{Sn}-\mathrm{H}$ and $\mathrm{Ge}-\mathrm{H}$ stretching frequencies, respectively. The corresponding deuterated complex LGeD (5) was prepared by reacting 2 with $\mathrm{LiAlD}_{4}$ and yielded the isotopically shifted Ge-D $\left(1462 \mathrm{~cm}^{-1}\right)$ IR band and thereby supported the initially assigned $\mathrm{Ge}-\mathrm{H}$ stretching vibration of $\mathbf{4}$. The wave numbers match well with those of respective four-coordinate $\mathrm{M}-\mathrm{H}$ species by Rivard et al. (D-F), ${ }^{9}$ Power et al., ${ }^{17}$ and our results ${ }^{18}$ but more than those reported for $\mathbf{A}\left(1733 \mathrm{~cm}^{-1}\right),{ }^{6 a} \mathbf{B}\left(1849 \mathrm{~cm}^{-1}\right),{ }^{6 a}$ and $\mathbf{C}\left(1722 \mathrm{~cm}^{-1}\right){ }^{7}$ In the EI-MS spectra of $\mathbf{3}$ and $\mathbf{4}$, each molecular ion was observed as the most abundant peak with highest relative intensity at $m / z 599$ and 553, respectively. The corresponding $m / z$ for 5 was found at 555 .

In order to draw a clearer picture on the $\mathrm{Sn}-\mathrm{H}$ and $\mathrm{Ge}-\mathrm{H}$ bonds, quantum chemical calculations were carried out on 3 and 4. Their structures were optimized at the BP86/def2-SVP (with effective core potentials for the $\mathrm{Sn}$ and Ge atoms) level of theory. ${ }^{19}$ Frequency calculations were used to confirm the structures as true minima. Taking into account the bulkiness of both compounds, one could expect that dispersion interactions play a significant role in their structures. Therefore, we have also carried out optimizations with the same functional and basis set, but including dispersion corrections, as proposed by Grimme (BP86-D/def2-SVP). ${ }^{20}$ Both sets of calculations agree closely in the local geometry of the $\mathrm{M}-\mathrm{H}(\mathrm{M}=\mathrm{Sn}$ and $\mathrm{Ge})$ bond. The $\mathrm{M}-\mathrm{H}$ distances are 1.792 and $1.787 \AA$ for $\mathrm{M}=\mathrm{Sn}$, using BP86 and BP86-D, respectively. However, the computed stretching frequencies $\left(1621 / 1646 \mathrm{~cm}^{-1}\right)$ are somewhat lower than the experimentally measured value of $1826 \mathrm{~cm}^{-1}$. In the case of Ge, the distances are 1.588 (BP86) and $1.583 \AA$ (BP86-D) with a stretching frequency of $1882 / 1918 \mathrm{~cm}^{-1}$.

The most significant difference between the DFT results with and without dispersion corrections is the conformation of the isopropyl groups. In the case of BP86-D/def2-SVP, for both 3 and $\mathbf{4}$, one of these groups has a methyl moiety pointing towards the metal bonded hydrogen atom. The experimentally derived structures, as well as the computed BP86/def2-SVP geometries, show the less steric hydrogen in this position. This is somewhat unexpected since there should be little energy gain 
in such an interaction. Instead, one would expect all methyl groups to point outward, conserving the symmetry and avoiding steric contacts. In order to better understand this occurrence, DF-MP2/ cc-pVTZ (cc-pVTZ-PP in the case of $\mathrm{Sn}$ and Ge) ${ }^{21}$ single points were computed on the DFT optimized geometries. The results show that, in fact, the BP86-D optimized structures are higher in energy. The BP86/def2-SVP structures are 2.9 and $0.2 \mathrm{kcal} \mathrm{mol}^{-1}$ lower in energy for structures $\mathbf{3}$ and $\mathbf{4}$, respectively, than the BP86-D analogues. The torsion of the isopropyl group seems, therefore, to be an artifact of the dispersion correction terms.

We have also performed a NBO analysis of the two compounds at the BP86/def2-SVP level of theory. ${ }^{22}$ The $\mathrm{Sn}-\mathrm{H}$ bond is built from a Sn hybrid orbital with $89.3 \%$ p-character. This value is close to the one reported for compound A (87.7\%) and higher than that of $\mathbf{F}(65.1 \%)$, which again relates to the small $J_{\mathrm{Sn}-\mathrm{H}}$ coupling constant measured. The p-character of the hybrid is similar for $\mathrm{Ge}-\mathrm{H}$ in compound $\mathbf{4}(85.8 \%)$. The lone pair of $\mathrm{Sn}$ and $\mathrm{Ge}$ is predominantly of s-character $(79.4 \%(\mathrm{Sn}) 70.9 \%(\mathrm{Ge}))$. In the dominant Lewis structures, the metals are only covalently bound to the hydrogen and the ring carbon. However, the second-order perturbation energy analysis of the NBOs shows a significant donation from each $\mathrm{N}$ lone pair to a p-orbital of the metal. The values are about $50 \mathrm{kcal} \mathrm{mol}^{-1}$ for $\mathrm{Ge}$ (per Ge-N contact) and $35 \mathrm{kcal} \mathrm{mol}^{-1}$ for $\mathrm{Sn}$.

While Dostál et al. exploited the pincer-based NCN ligand to isolate the first monomeric stibinidene and bismuthinidene derivatives, ${ }^{23}$ we have shown that such a ligand is also useful to isolate monomeric $\mathrm{Sn}$ (II) and $\mathrm{Ge}$ (II) hydrides. This is the first example of a $\mathrm{Sn}$ (II) hydride where no $\mathrm{Sn}-\mathrm{H}$ intermolecular interaction is present. The monomeric structures of $\mathbf{3}$ and $\mathbf{4}$ are mainly stabilized by donating electron density to the empty $p$ orbital of the central metal atoms as supported by theoretical calculations. The chemistry of these new hydrides will be explored and published in due course.

Support from the Deutsche Forschungsgemeinschaft (DFG RO 224/55-3 (H. W. R.), Priority Program 1178 (D. S.), Emmy Noether Fellowship (A. L.), Deutscher Akademischer Austausch Dienst (research fellowship to S. K.) and the NSERC of Canada (scholarship to J.-P. D.) are acknowledged.

\section{Notes and references}

1 (a) T. Hiyama and T. Kusumoto, Comprehensive Organic Synthesis, Pergamon, Oxford, UK., 1991, vol. 8, pp. 763-792; (b) G. F. Bradley and S. R. Stobart, J. Chem. Soc., Dalton Trans., 1974, 264-269.

2 For reviews see: (a) S. K. Mandal and H. W. Roesky, Acc. Chem. Res., 2012, 45, 298-307; (b) S. S. Sen, S. Khan, P. P. Samuel and H. W. Roesky, Chem. Sci., 2012, 3, 659-682; (c) S. K. Mandal and H. W. Roesky, Chem. Commun., 2010, 46, 6016-6041; (d) E. Rivard and P. P. Power, Dalton Trans., 2008, 4336-4343; (e) S. Aldridge and A. J. Downs, Chem. Rev., 2001, 101, 3305-3365; (f) C. Jones, Chem. Commun., 2001, 2293-2298; (g) A. Staubitz, A. P. M. Robertson and I. Manners, Chem. Rev., 2010, 110, 4079-4124.

3 (a) C.-F. Wang, S.-Y. Xie, S.-C. Lin, X. Cheng, X.-H. Zhang, R.-B. Huang and L.-S. Zheng, Chem. Commun., 2004, 1766-1767; (b) C. M. Hessel, E. J. Henderson, J. A. Kelly, R. G. Cavell,
T.-K. Sham and J. G. C. Veinot, J. Phys. Chem. C, 2008, 112, 14247-14254

4 B. E. Eichler and P. P. Power, J. Am. Chem. Soc., 2000, 122 $8785-8786$.

5 A. F. Richards, A. D. Phillips, M. M. Olmstead and P. P. Power, J. Am. Chem. Soc., 2003, 125, 3204-3205.

6 (a) L. W. Pineda, V. Jancik, K. Starke, R. B. Oswald and H. W. Roesky, Angew. Chem., 2006, 118, 2664-2667 (Angew. Chem., Int. Ed., 2006, 45, 2602-2605); (b) A. Jana, H. W. Roesky, C. Schulzke and A. Döring, Angew. Chem., 2009, 121, 1126-1129 (Angew. Chem., Int. Ed., 2009, 48, 1106-1109); (c) A. Jana, D. Ghoshal, H. W. Roesky, I. Objartel and D. Stalke, J. Am. Chem. Soc., 2009, 131, 1288-1293.

7 S. L. Choong, W. D. Woodul, C. Schenk, A. Stasch, A. F. Richards and C. Jones, Organometallics, 2011, 30, $5543-5550$.

8 G. Leroy, D. Riffi Temsamani and C. Wilante, THEOCHEM, 1994, 306, 21-39.

9 (a) S. M. I. Al-Rafia, A. C. Malcolm, R. Mcdonald, M. J. Ferguson and E. Rivard, Angew. Chem., 2011, 123, 8504-8507 (Angew. Chem., Int. Ed., 2011, 50, 8354-8357); (b) S. M. I. Al-Rafia, A. C. Malcolm, S. K. Liew, M. J. Ferguson and E. Rivard, J. Am. Chem. Soc., 2011, 133, 777-779; (c) K. C. Thimer, S. M. I. Al-Rafia, M. J. Ferguson, R. McDonald and E. Rivard, Chem. Commun., 2009, 7119-7121.

10 S. Khan, R. Michel, J. M. Dieterich, R. A. Mata, H. W. Roesky, J.-P. Demers, A. Lange and D. Stalke, J. Am. Chem. Soc., 2011, 133, 17889-17894.

11 S.-P. Chia, H.-X. Yeong and C.-W. So, Inorg. Chem., 2012, 51 , $1002-1010$.

12 R. Jambor, S. H-Pawlis, M. Schürmann and K. Jurkschat, Eur. J. Inorg. Chem., 2011, 344-348.

13 (a) T. Kottke and D. Stalke, J. Appl. Crystallogr., 1993, 26, 615-619; (b) D. Stalke, Chem. Soc. Rev., 1998, 27, 171-178.

14 (a) F. E. Hahn, L. Wittenbecher, M. Kühn, T. Lügger and R. Fröhlich, J. Organomet. Chem., 2001, 617-618, 629-634; (b) K. Jurkschat, S. van Dreumel, G. Dyson, D. Dakternieks, T. J. Bastow, M. E. Smith and M. Dräger, Polyhedron, 1992, 11, $2747-2755$.

15 R. Jambor, B. Kašná, K. N. Kirschner, M. Schürmann and K. Jurkschat, Angew. Chem., 2008, 120, 1674-1677 (Angew. Chem., Int. Ed., 2008, 47, 1650-1653).

16 E. Rivard, R. C. Fischer, R. Wolf, Y. Peng, W. A. Merrill, N. D. Schley, Z. Zhu, L. Pu, J. C. Fettinger, S. J. Teat, I. Nowik, R. H. Herber, N. Takagi, S. Nagase and P. P. Power, J. Am. Chem. Soc., 2007, 129, 16197-16208.

17 G. H. Spikes, J. C. Fettinger and P. P. Power, J. Am. Chem. Soc., 2005, 127, 12232-12233.

18 Y. Ding, H. Hao, H. W. Roesky, M. Noltemeyer and H.-G. Schmidt, Organometallics, 2001, 20, 4806-4811.

19 (a) A. D. Becke, Phys. Rev. A: At., Mol., Opt. Phys., 1988, 38, 3098-3100; (b) J. P. Perdew, Phys. Rev. B, 1986, 33, 8822-8824; (c) F. Weigend and R. Ahlrichs, Phys. Chem. Chem. Phys., 2005, 7, 3297-3305; (d) B. Metz, H. Stoll and M. Dolg, J. Chem. Phys., 2000, 113, 2563-2569; (e) ORCA, an ab initio, DFT and semiempirical electronic structure package, version $2.8,2010$.

20 S. Grimme, J. Comput. Chem., 2006, 27, 1787-1799.

21 (a) H.-J. Werner, F. R. Manby and P. J. Knowles, J. Chem. Phys., 2003, 118, 8149-8160; (b) T. H. Jr. Dunning, J. Chem. Phys., 1989, 90, 1007-1023; (c) K. A. Peterson, J. Chem. Phys., 2003, 119, 11099-11112; (d) H.-J. Werner, P. J. Knowles, R. Lindh, F. R. Manby and M. Schütz, MOLPRO, version 2010.1, a package of ab initio programs, 2010, http://www.molpro.net.

22 J. P. Foster and F. Weinhold, J. Am. Chem. Soc., 1980, 102, $7211-7218$.

23 P. Šimon, F. De Proft, R. Jambor, A. Růžička and L. Dostál, Angew. Chem., 2010, 120, 1674-1677 (Angew. Chem., Int. Ed., 2010, 49, 5468-5471). 